\title{
Phân tích chẩn đoán bệnh mạch vành dựa trên tín hiệu điện tâm đồ
}

\author{
Trần Như Chí ${ }^{1}$, Nguyễn Thị Thanh Vân ${ }^{1 * *}$, Lê Văn Chiều ${ }^{2}$ \\ ${ }^{1}$ Truòng Đại học Công nghệ, ĐHQGHN, 144 Xuân Thủy, Hà Nội, Việt Nam \\ ${ }^{2}$ Ban Quản lý các dụ án, ĐHQGHN, 144 Xuân Thủy, Hà Nội, Việt Nam \\ Nhận ngày 08 tháng 5 năm 2017 \\ Chỉnh sửa ngày 08 tháng 6 năm 2017; Chấp nhận đăng ngày 15 tháng 9 năm 2017
}

\begin{abstract}
Tóm tắt: Điện tâm đồ (ECG) ghi lại và biểu thị các xung điện trong quá trình hoạt động của tim. Nghiên cứu các đặc trưng trong tín hiệu điện tâm đồ để phát hiện ra những điểm bất thường của tim có ý nghĩa quan trọng trong lĩnh vực y khoa. Báo cáo này trình bày phương pháp phát hiện hội chứng dày tâm thất và dày tâm nhĩ của tim trên cơ sở phân tích tín hiệu điện tâm đồ kết hợp với các đặc điểm của bệnh. Một chương trình thực hiện tự động phân tích tín hiệu ECG nhằm phát hiện hội chứng dày tâm thất và dày tâm nhĩ đã được phát triển và kiểm chứng với các mẫu tín hiệu ECG. Kết quả kiểm nghiệm cho thấy kết quả chẩn đoán có độ chính xác cao, hứa hẹn khả năng tích hợp chương trình vào thiết bị đo ECG thực hiện sàng lọc và hỗ trợ chẩn đoán tự động.
\end{abstract}

Tù khóa: Điện tâm đồ, ECG, hội chứng dày tâm thất, hội chứng dày tâm nhĩ, xử lý tín hiệu.

\section{Giới thiệu}

Tim là một trong những bộ phận rất quan trọng giúp duy trì sự sống của con người. Do tính chất quan trọng của tim, các bệnh lý liên quan luôn nhận được sự quan tâm nghiên cứu của các chuyên gia y tế. Các bệnh lý của tim hầu hết được phản ánh thông qua tín hiệu điện tâm đồ. Tim tạo ra các xung điện nhỏ, truyền dẫn đến cơ tim để thực hiện sự co bóp của tim. Những xung điện này được ghi lại, thể hiện trên đồ thị và xem như là điện tâm đồ hay còn gọi là ECG hay EKG (electrocardiogram). Đặc trưng của tín hiệu ECG được thể hiện thông qua các sóng $\mathrm{P}$, phức bộ $\mathrm{QRS}$ và sóng $\mathrm{T}$, và đôi khi với sóng $\mathrm{U}$ nhỏ [1]. Trong đó phức bộ $\mathrm{QRS}$ thể

\footnotetext{
*Tác giả liên hệ. ĐT.: 84-912720780.

Email:vanntt@vnu.edu.vn

https://doi.org/10.25073/2588-1140/vnunst.4659
}

hiện sự co thắt của tâm thất trái và phải, sóng $\mathrm{P}$ là do co thắt tâm nhĩ, sóng $\mathrm{T}$ mô tả sự phân cực của tâm thất và sóng $U$ là biểu thị của cơ nhú. Các phương pháp phát hiện vị trí sóng của ECG tập trung vào việc phát hiện phức bộ $\mathrm{QRS}$ dầu tiên do có giá trị biên độ đỉnh lớn nhất, từ đó suy ra vị trí của các sóng $R, Q, S, P, T$ còn lại hay các đoạn quan trọng RR, ST, PR. Phương pháp chủ yếu để xác định phức bộ $\mathrm{QRS}$ là sử dụng phương pháp lọc cơ bản hay các phương pháp khác như mạng neuron nhân tạo [2], giải thuật gen [3], biến đồi sóng con $[4,5]$, mô hình Markov ẩn [6]... Kết quả của những nghiên cứu xác định vị trí các sóng trong ECG ở trên thường được sử dụng cho mục đích y khoa, cụ thể là trong chẩn đoán bệnh liên quan tới tim.

Theo thống kê y học, một trong những bệnh nguy hiểm liên quan đến hoạt động của tim là hội chứng dày thất và dày nhĩ. Nếu dày thất là 
nguồn gốc của ba biến chứng tim như thiếu máu cơ tim và nhồi máu cơ tim, giảm co bóp và gây rối loạn chức năng tâm trương, loạn nhịp tim thì dày nhĩ sẽ phát sinh thiếu máu cơ tim và các bệnh lý về van tim. Hội chứng dày thất và dày nhĩ được biểu hiện trên ECG thông qua đặc điểm khác thường của sóng $\mathrm{R}, \mathrm{S}, \mathrm{P}$ trên các chuyển đạo $\mathrm{V}_{1}, \mathrm{~V}_{2}, \mathrm{~V}_{5}, \mathrm{~V}_{6}$, dII [7]. Để hỗ trợ quá trình chẩn đoán bệnh chính xác, bài báo đề xuất một phương pháp chẩn đoán bệnh dày thất và dày nhĩ hiệu quả cho phép tự động xác định trực tiếp các thông số liên quan đển hội chứng trên cơ sở phân tích tín hiệu ECG. Một phần mềm ứng dụng với các chức năng hữu ích trong chẩn đoán và điều trị bệnh được xây dựng để thực thi phương pháp đề xuất với các mẫu dữ liệu ECG của Physionet. Kết quả thử nghiệm chẩn đoán bệnh trên các mẫu với độ chính xác cao đã khẳng định hiệu quả của phương pháp đề xuất và tính khả thi trong ứng dụng thực tiễn.

Báo cáo này được trình bày bao gồm bốn phần. Phần 1 giới thiệu tổng quan vấn đề nghiên cứu. Phần 2 trình bày tóm tắt hội chứng dày thất và dày nhĩ theo quan điểm y học từ đó đề xuất phương pháp chẩn đoán các hội chứng này trên cơ sở phân tích tín hiệu ECG. Một số thực nghiệm kiểm chứng phương pháp đề xuất và thảo luận được trình bày trong Phần 3 . Phần cuối là một số kết luận và định hướng nghiên cứu tiếp theo.

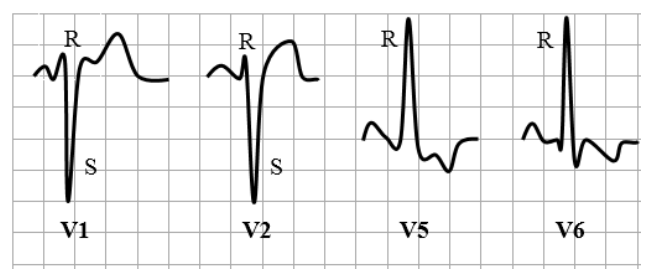

$\mathrm{R}$ tại $\mathrm{V}_{5} / \mathrm{V}_{6} \geq 25 \mathrm{~mm}, \mathrm{~S}$ tại $\mathrm{V}_{1} / \mathrm{V}_{2}$ dài ra $\geq 25 \mathrm{~mm}$, chỉ số Sokolov-Lyon thất trái: $\mathrm{SV}_{1}+\mathrm{RV}_{5} / \mathrm{V}_{6} \geq 35 \mathrm{~mm}$, nhánh nội điện tới muộn $\geq 0,045 \mathrm{~s}$.

(a)

\section{Hội chứng dày tâm thất, dày tâm nhĩ và phương pháp chẩn đoán dựa trên phân tích tín hiệu điện tim}

Phần này sẽ trình bày hội chứng dày tâm thất và dày tâm nhĩ của tim theo quan điểm $\mathrm{y}$ học và sự thay đổi của tín hiệu ECG khi xuất hiện các hội chứng này. Trên cơ sở đó, một thuật toán tự động phát hiện hội chứng dày thất và dày nhĩ trên cơ sở phân tích tín hiệu $\mathrm{ECG}$ được đề xuất. Một chương trình đã được phát triển để thực hiện thuật toán.

\section{A. Hội chứng dày tâm thất}

việc co bóp và đẩy máu đi và do nó thành của nó dày lên và giãn ra. Hội chứng này tác động rất lớn đến quá trình khử cực làm thay đổi biên độ của sóng: $\mathrm{R}$ tăng lên ở chuyển đạo trực tiếp, $\mathrm{S}$ sâu thêm ở chuyển đạo phía đối lập và QRS rộng hơn. Các biến đổi về khử cực này sẽ gây ra các biến đổi thứ phát của quá trình tái cực dẫn đến $\mathrm{ST}$ chênh và $\mathrm{T}$ ngược chiều với QRS. Hình 1 thể hiện tín hiệu ECG và một số thông số của hội chứng dày thất [7].

\section{B. Hội chứng dày tâm nhĩ}

Hội chứng dày tâm nhĩ là sự tăng lên về thể tích của tâm nhĩ, có thể là tăng lên thể tích của tâm nhĩ trái hoặc phải hoặc cả hai nhĩ. Hội chứng này là nguyên nhân gây ra thiếu máu cơ tim và các bệnh lý về van tim. Hội chứng dày nhĩ sẽ gây ra biến đổi vecto khử cực do đó thu được sóng $\mathrm{P}$ khác thường trên $\mathrm{ECG}$. Hình 2 thể hiện tín hiệu ECG cùng một số thông số trong hội chứng dày nhĩ [7].

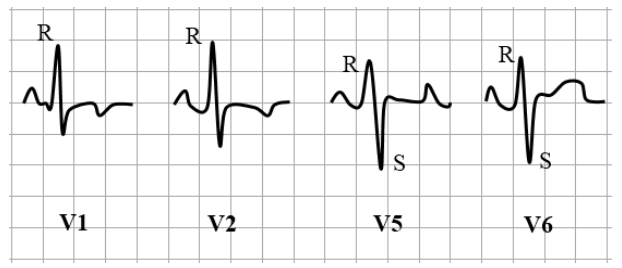

$\mathrm{R}$ tại $\mathrm{V}_{1} \geq 7 \mathrm{~mm}, \mathrm{R} / \mathrm{S}$ tại $\mathrm{V}_{1}, \mathrm{~V}_{2} \geq 1, \mathrm{R} / \mathrm{S}$ ở $\mathrm{V}_{5}, \mathrm{~V}_{6} \leq 1$, chỉ số Sokolov-Lyon thất phải: $\mathrm{RV}_{1}+\mathrm{SV}_{5} / \mathrm{V}_{6} \geq 11 \mathrm{~mm}$, ST-T trái chiều QRS.

(b)

Hình 1. ECG của hội chứng dày thất: (a) Dày thất trái, (b) Dày thất phải [7]. 


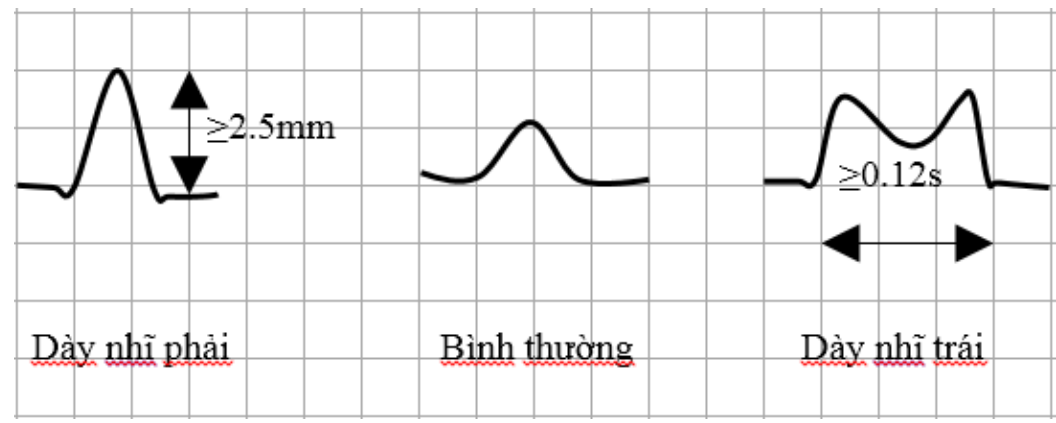

a) Sóng $P \geq 2,5 \mathrm{~mm}, \mathrm{P}$ tại $\mathrm{V}_{1}$ có dạng 2 pha $+/$ - và $>$ $0,03 \mathrm{~s}$, trục sóng $\mathrm{P}$ lệch phải giữa $60^{\circ}$ và $90^{\circ}$, phức bộ QRS ở $\mathrm{V}_{1}$ có dạng QR: dấu hiệu Soli Pallares. b) Sóng $\mathrm{P} \geq 0,12 \mathrm{~s}, \mathrm{P}$ có 2 đỉnh hoặc có móc hoặc có hình lưng lạc đà, $\mathrm{P}$ tại $\mathrm{V}_{1}$ có dạng 2 pha $+/$ - và $\geq 0,04 \mathrm{~s}$, trục sóng $\mathrm{P}$ lệnh trái giữa $40^{\circ}$ và $0^{\circ}$.

Hình 2. ECG của hội chứng dày nhĩ: (a) Dày nhĩ phải, (b) Dày nhì trái [7].

\section{Phưong pháp chẩn đoán hội chứng dày tâm thất và dày tâm nhĩ}

Dựa trên những đặc trưng của tín hiệu ECG của bệnh nhân mắc hội chứng dày tâm thất và dày tâm nhĩ, một chương trình đã được phát triển để tự động phát hiện các đặc trưng này. Lưu đồ thuật toán thực hiện được trình bày trên Hình 3. Trước tiên cần xác định các đường đẳng điện của toàn tín hiệu và trong một chu kỳ. Sau đó tiến hành xác định lần lượt biên độ, vị trí các đỉnh đặc trưng $\mathrm{R}, \mathrm{P}, \mathrm{Q}, \mathrm{S}, \mathrm{T}$ trong tín hiệu ECG. Trên cơ sở đó phân tích đặc điểm của sóng $R, S, P, S T$ trên các chuyển đạo $V_{1}$, $\mathrm{V}_{2}, \mathrm{~V}_{5}, \mathrm{~V}_{6}$, dII để đưa ra các chẩn đoán liên quan tới bệnh dày thất và dày nhĩ. Các chẩn đoán được đưa ra dựa trên chỉ số SOKOLOW LYON [7].

Đường đẳng điện biểu hiện không có xung điện tới điện cực gắn trên chuyển đạo. Đường đẳng điện chung $e_{t b}(1)$ của toàn tín hiệu được tìm bằng cách so sánh số điểm trên và dưới xấp xỉ bằng nhau thông qua vòng lặp có điều kiện. Để xác định độ rộng của từng sóng trong $\mathrm{ECG}$ thì yêu cầu một đường đẳng điện chính xác hơn, đó là đường đẳng điện trong một chu kỳ. Giá trị ngưỡng trung bình được chọn là 50 dựa trên số điểm của tín hiệu ECG. Thuật toán tìm đường đẳng điện trong một chu kỳ về cơ bản giống thuật toán tìm đường đẳng điện chung nhưng thay đổi về khoảng xét.

$$
e_{t b}=\left|\mathrm{N}>\frac{(\min +\max )}{2}-\mathrm{M}<\frac{(\min +\max )}{2}\right|<50
$$

$\mathrm{N}, \mathrm{M}$ : số điểm

Tín hiệu ECG được tiền xử lý để loại bỏ nhiễu tần số thấp thông qua biến đổi Fourier nhanh - FFT $(X(k))$ và khôi phục về miền thời gian bởi biến đổi Fourier ngược - IFFT $(x(n))$ như (2).

$$
\begin{array}{ll}
X(k)=\sum_{n=0}^{N-1} x(n) \mathrm{e}^{-j \frac{2 \pi n k}{N}} & 0 \leq k \leq N-1 \\
x(n)=\frac{1}{N} \sum_{n=0}^{N-1} X(k) \mathrm{e}^{j \frac{2 \pi n k}{N}} & 0 \leq n \leq N-1
\end{array}
$$

Tín hiệu sau khi tiền xử lý được đưa qua cửa sổ lọc với kích thước $\mathrm{N}$ để xác định các đỉnh dương $x_{W}(n)$ (3) có trong tín hiệu và qua lọc ngưỡng $\mathrm{T}$ (4) để thu được các đỉnh $\mathrm{R}$ "tạm thời" $x_{T}(n)$. Tuy nhiên, việc lọc ngưỡng chưa tối ưu và có thể vẫn còn sót các điểm $R$, vì vậy tín hiệu cần được qua một cửa sổ lọc điều chỉnh với kích thước cửa sổ điều chỉnh $\mathrm{N}_{\text {new }}$ được tính toán dựa trên khoảng cách giữa các đỉnh $\mathrm{R}$ "tạm thời" (5)

$$
\begin{aligned}
& x_{\mathrm{W}}(n)=\text { filterwindow }\{x(n), \mathrm{N}\} \\
& x_{T}(n)=\left\{x_{\mathrm{W}}(n) \mid x_{\mathrm{W}}(n) \leq \mathrm{T}\right\} \\
& \mathrm{N}_{\text {new }}=2 *\left\{x_{T}(n)-x_{T}(n-1)\right\}-0.04 * T_{s}
\end{aligned}
$$

trong đó $T_{s}$ là tốc độ lấy mẫu.

Sau khi xác định được các đỉnh $\mathrm{R}$, dựa vào đặc trưng của các đỉnh trong điện tâm đồ để xác 
định vị trí của các đỉnh $\mathrm{Q}, \mathrm{P}, \mathrm{S} \mathrm{T}$ còn lại. Khi vị trí của tất cả các đỉnh sóng cùng giá trị của nhịp tim, đường đẳng điện đã được xác định, phân tích đặc điểm chi tiết của các sóng $\mathrm{R}, \mathrm{S}, \mathrm{P}, \mathrm{ST}$ trên các chuyển đạo $\mathrm{V}_{1}, \mathrm{~V}_{2}, \mathrm{~V}_{5}, \mathrm{~V}_{6}$, dII như trên lưu đồ Hình 3 để chuẩn đoán hội chứng dày thất và dày nhĩ.

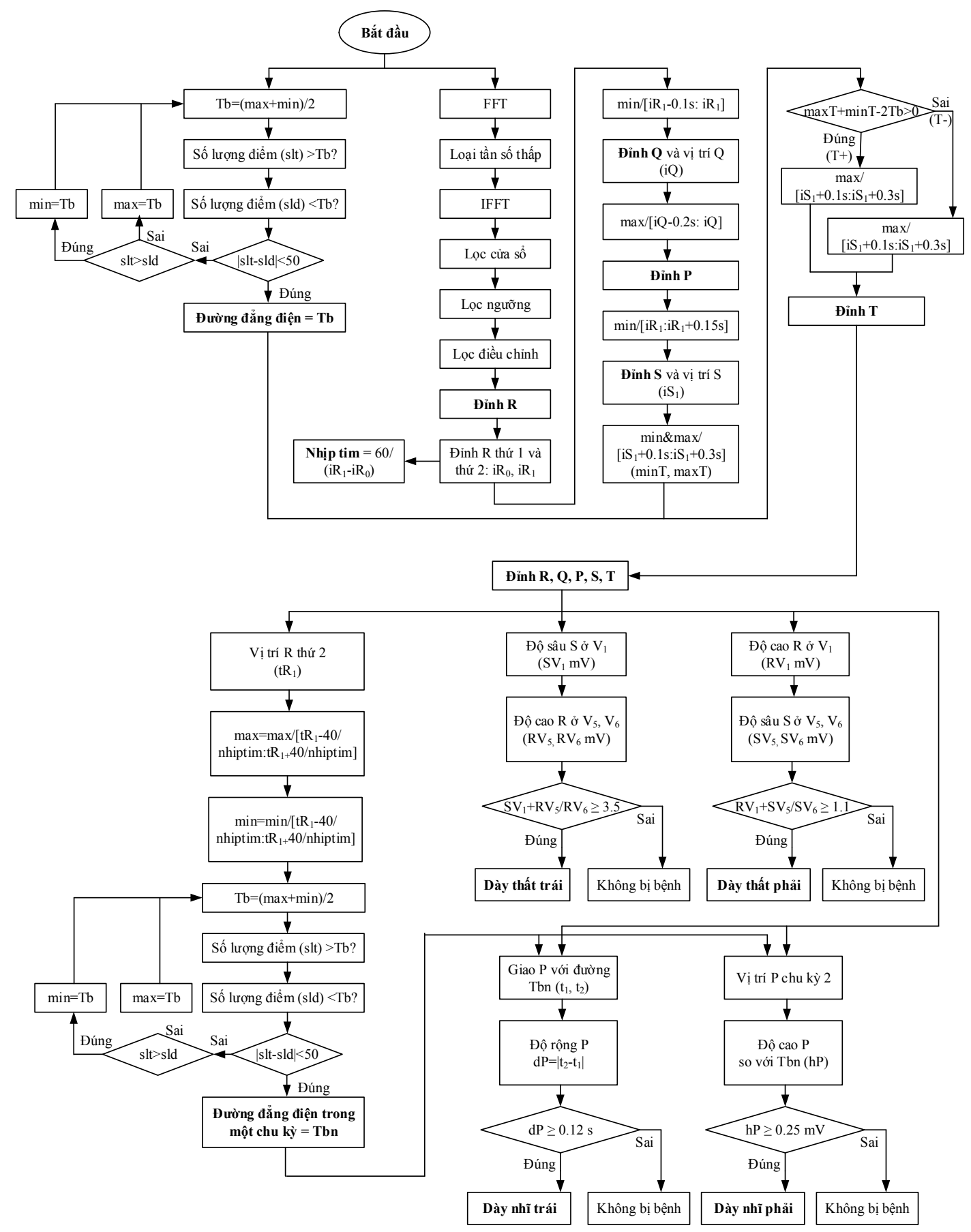

Hình 3. Lưu đồ thuật toán phương pháp chẩn đoán hội chứng dày thất và dày nhĩ. 


\section{Kết quả và thảo luận}

Phương pháp chẩn đoán hội chứng dày thất và dày nhĩ đề xuất được thực nghiệm với các mẫu dữ liệu $\mathrm{ECG}$ từ cơ sở dữ liệu chuẩn của Viện Đo lường của Đức - PhysiNetPhysiche Bundesanstalt (PTB). ECGs được thu thập từ những người tình nguyện khỏe mạnh và những bệnh nhân bị các bệnh tim khác nhau do Giáo sư Michael Oeff, MD, tại Khoa Tim mạch của Bệnh viện Đại học Benjamin Franklin ở Berlin, Đức. Một phần mềm ứng dụng xây dựng trên ngôn ngữ $\mathrm{C}++$ với các tính năng phân tích, lưu trữ và trích xuất trực tiếp kết quả chẩn đoán để hỗ trợ thuận lợi quá trình thăm khám và điều trị bệnh.

Hình 4 là ví dụ một mẫu tín hiệu ECG của bệnh nhân đưa vào phần mềm để chẩn đoán bệnh. Phần mềm chẩn đoán đã phát hiện hội chứng dày thất và dày nhĩ trên tập các mẫu dữ liệu ECG. Hình 5 là các dạng tín hiệu sau khi lọc nhiễu, lọc điều chỉnh, xác định vị trí các sóng cơ bản $\mathrm{R}, \mathrm{S}, \mathrm{Q}, \mathrm{P}, \mathrm{T}$, và các đường đẳng điện của toàn bộ tín hiệu cũng như trong một chu kỳ. Tín hiệu trên Hình 5a là tín hiệu loại bỏ nhiễu công nghiệp $50 \mathrm{~Hz}$, lọc bỏ nhiễu tần số thấp và tần số cao ngoài dải tín hiệu điện tim. Lọc điều chỉnh giúp loại bỏ nền một chiều của tín hiệu. Trên cơ sở các giá trị tìm được, tính toán các thông số cần thiêt để đưa ra chẩn đoán về hội chứng dày thất và dày nhĩ.

\section{A. Kết quả lọc tín hiệu và phát hiện đỉnh}

Hình 5 là các dạng tín hiệu sau khi lọc nhiễu, lọc điều chỉnh, xác định vị trí các sóng cơ bản $\mathrm{R}, \mathrm{S}, \mathrm{Q}, \mathrm{P}, \mathrm{T}$, và các đường đẳng điện của toàn bộ tín hiệu cũng như trong một chu kỳ. Trên cơ sở các giá trị tìm được, tính toán các thông số cần thiết để đưa ra chẩn đoán về hội chứng dày thất và dày nhĩ.

B. Kết quả chẩn đoán hội chứng dày tâm thất (dày thất trái, dày thất phải)

Hình 6 thể hiện kết quả phát hiện sóng $R$ và $\mathrm{S}$ trên các chuyển đạo $\mathrm{V}_{1}$ (Hình 6(a)), $\mathrm{V}_{5}$ (Hình 6(b)), và $\mathrm{V}_{6}($ Hình $6(\mathrm{c}))$ với các giá trị như sau:

- Nhịp tim: 68.331 BPM

- $\mathrm{SV}_{1}+\mathrm{RV}_{5}=6.0122 \mathrm{mV}, \mathrm{SV}_{1}+\mathrm{RV}_{6}=$ $4.6963 \mathrm{mV}$

- $\mathrm{RV}_{1}+\mathrm{SV}_{5}=0.311803 \mathrm{mV}, \mathrm{RV}_{1}+\mathrm{SV}_{6}=$ $0.153703 \mathrm{mV}$

So sánh với tiêu chuẩn SOKOLO - LYON thì chẩn đoán: tim bị dày thất trái.

Hình 7 thể hiện kết quả phát hiện sóng $R$ và $\mathrm{S}$ tại các chuyển đạo $\mathrm{V}_{1}$ (Hình $7(\mathrm{a})$ ), $\mathrm{V}_{5}$ (Hình 7(b)), và $\mathrm{V}_{6}$ (Hình 7(c)) với các giá trị như sau:

+ Nhịp tim: 51.5021 BPM

$+\mathrm{SV}_{1}+\mathrm{RV}_{5}=0.771242 \mathrm{mV}, \mathrm{SV}_{1}+\mathrm{RV}_{6}=$ $0.788699 \mathrm{mV}$

$+\mathrm{RV}_{1}+\mathrm{SV}_{5}=2.98276 \mathrm{mV}, \mathrm{RV}_{1}+\mathrm{SV}_{6}=$ $2.9453 \mathrm{mV}$

So sánh với tiêu chuẩn SOKOLO- LYON thì chuẩn đoán: tim bị dày thất phải.

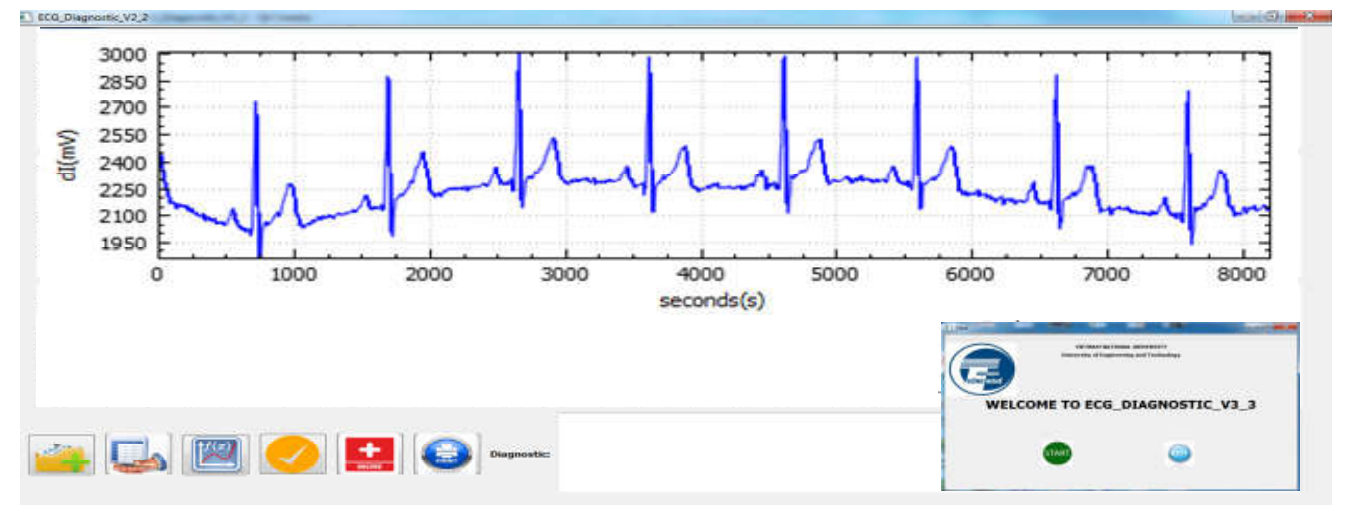

Hình 4. Mẫu tín hiệu ECG cần chẩn đoán bệnh được hiển thị trong phần mềm chẩn đoán bệnh. 


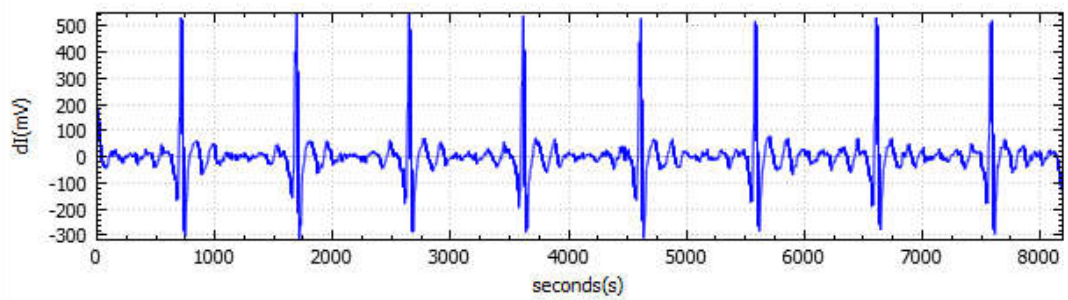

(a)

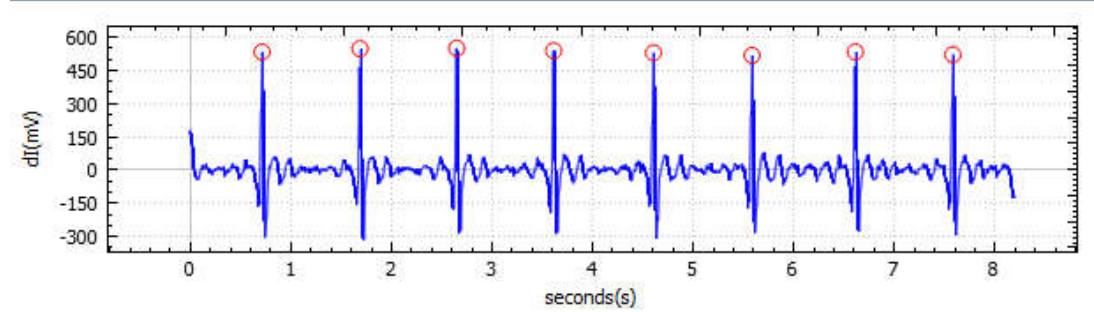

(b)

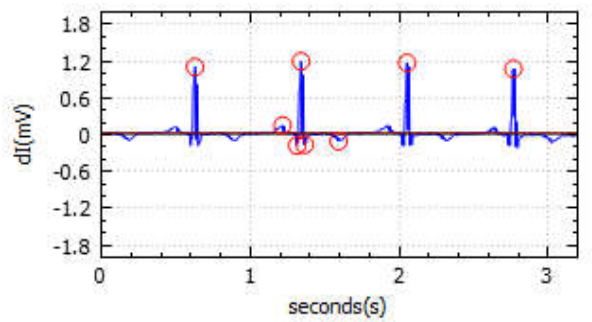

(c)

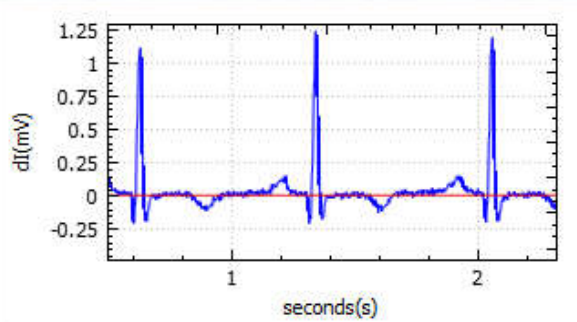

(d)

Hình 5. (a) Tín hiệu sau khi loại bỏ tần số thấp, (b) Tín hiệu sau lọc hiệu chỉnh và xóa đỉnh lân cận, (c) Các đỉnh sóng R, S, Q, P, T, (d) Đường đẳng điện.

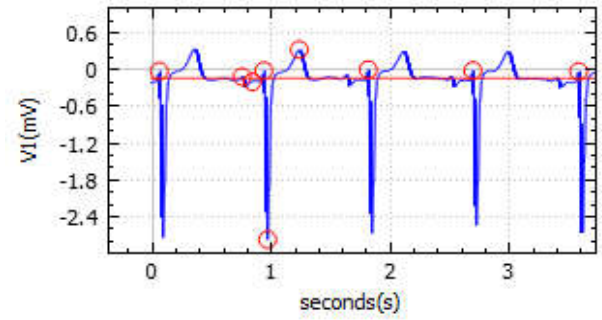

(a)

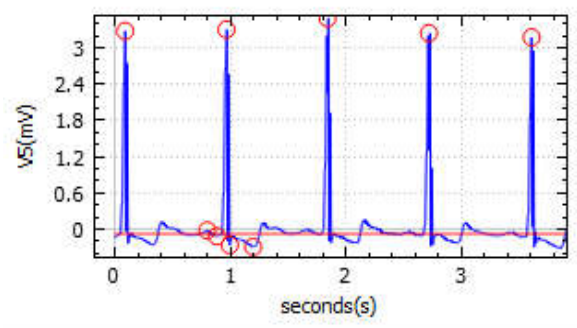

(b)

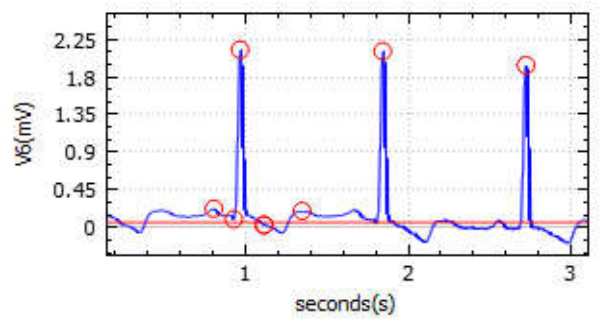

(c)

Hình 6. Kết quả chẩn đoán bệnh dày thất trái. (a) Chuyển đạo $\mathrm{V}_{1}$; (b) Chuyển đạo $\mathrm{V}_{5}$, (c) Chuyển đạo $\mathrm{V}_{6}$. 


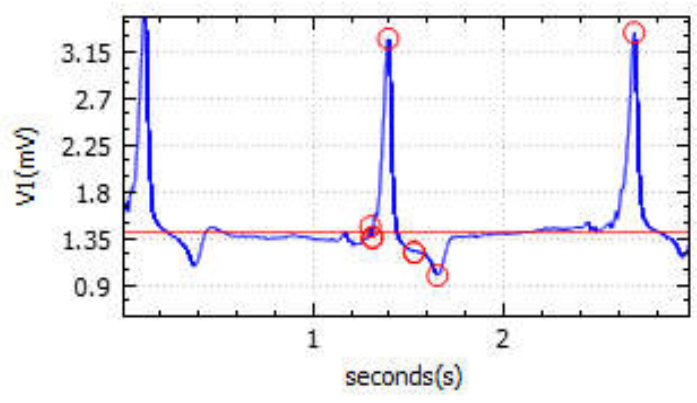

(a)

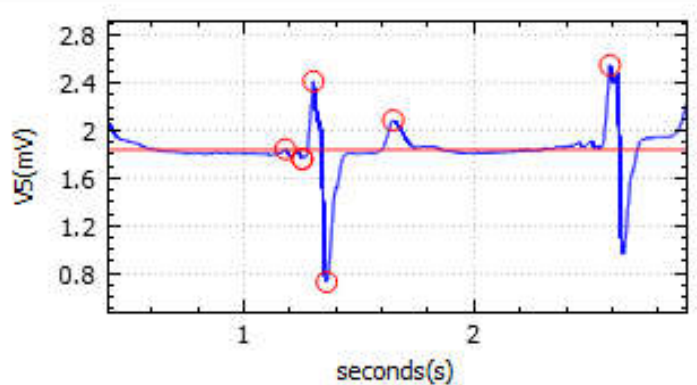

(b)

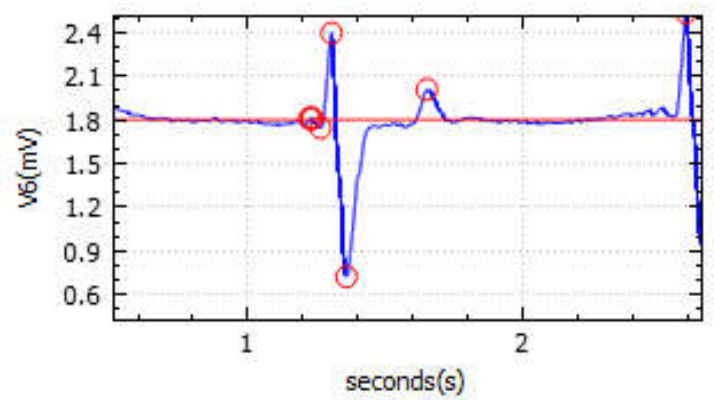

(c)

Hình 7. Kết quả chuẩn đoán bệnh dày thất phải. (a) Chuyển đạo $\mathrm{V}_{1}$; (b) Chuyển đạo $\mathrm{V}_{5}$, (c) Chuyển đạo $\mathrm{V}_{6}$.

C. Kết quả chẩn đoán hội chứng dày tâm nhĩ (dày nhĩ trái, dày nhĩ phải)

Hình 8 là kết quả phát hiện sóng $\mathrm{P}$ trên chuyển đạo dII với các thông số về nhịp tim, độ

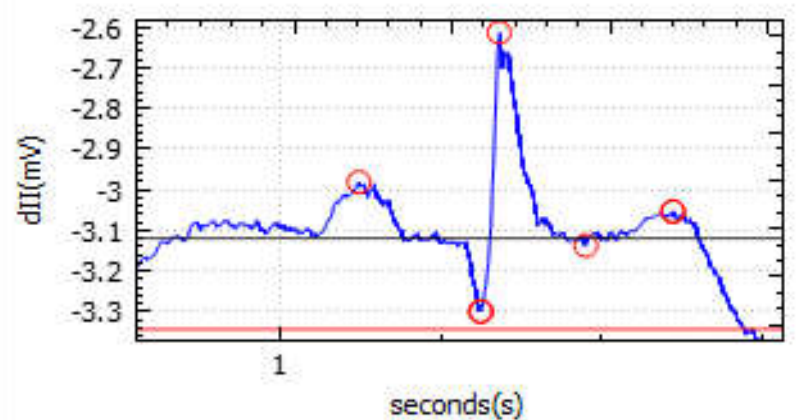

- Nhịp tim: 76 BPM

- $\quad$ Độ rộng sóng $\mathrm{P}$ ở $\mathrm{dII}=0.27 \mathrm{~s}$

- $\quad$ Độ cao sóng P ở dII $=0.1379 \mathrm{mV}$

- Chuẩn đoán: tim bị dày nhĩ trái

(a) rộng sóng và độ cao sóng. Theo thông số về hội chứng dày thất thì chẩn đoán bệnh tương ứng với dày nhĩ trái (Hình $8(\mathrm{a})$ ) và dày nhĩ phải (Hình 8(b)).

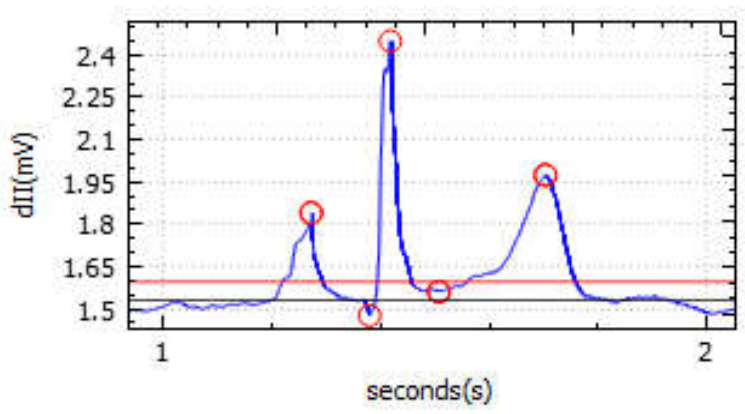

- Nhịp tim: 57 BPM

- $\quad$ Độ rộng sóng P ở dII = $0.148 \mathrm{~s}$

- $\quad$ Độ cao sóng $\mathrm{P}$ ở dII = $0.30975 \mathrm{mV}$

- Chẩn đoán: tim bị dày nhĩ phải

(b)

Hình 8. Kết quả chẩn đoán bệnh: (a) Dày nhĩ trái, (b) Dày nhĩ phải. 
Để đánh giá hoạt động của chương trình, thí nghiệm được tiến hành trên 60 mẫu ECG từ cơ sở dữ liệu chuẩn Viện Đo lường của Đức như đã đề cập ở trên. Với các mẫu dữ liệu ECG, phần mềm đã thực hiện vẽ 12 chuyển đạo, xác định và đánh dấu được các đỉnh sóng cơ bản, phân tích các đặc trưng, từ đó đưa ra chẩn đoán hội chứng dày thất trái, dày thất phải, dày nhĩ trái, và dày nhĩ phải dựa trên tiêu chuẩn SOKOLOW - LYON. Kết quả chẩn đoán thu được với 60 mẫu dữ liệu phần mềm cho ra kết quả có 16 dữ liệu bệnh dày nhĩ trái, 3 dữ liệu dày nhĩ phải, 3 dữ liệu dày thất trái và 4 dữ liệu dày thất phải, các mẫu còn lại cho ra kết quả tim không bị bệnh. Các kết quả phát hiện bệnh từ phần mềm là đồng nhất với kết quả chuẩn đoán bởi chuyên gia y tế có kinh nghiệm. Một số trường hợp chẩn đoán không cho ra kết quả do không phát hiện được chính xác các đỉnh trong phức bộ sóng điện tim. Lý do tín hiệu thu được có nhiễu lớn do người lấy mẫu cử động trong quá trình tiến hành đo điện tim (Hình 9). Với những trường hợp này thì đọc điện tim thực hiện bởi các nhân viên y tế có kinh nghiệm cũng hết sức khó khăn. Những kết quả thu được này xác thực độ tin cậy của thuật toán, mở ra khả năng tích hợp chương trình vào thiết bị đo ECG nhằm thực hiện sàng lọc và hỗ trợ chẩn đoán tự động, giúp giảm tải cho các nhân viên y tế.

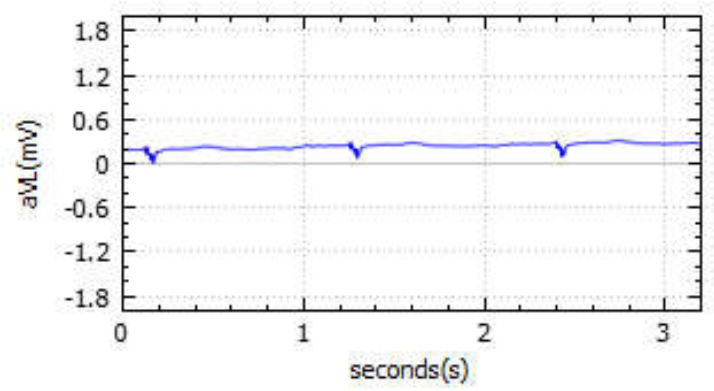

Hình 9. Một tín hiệu ECG nhiễu lớn do cử động của bệnh nhân trong quá trình đo. Với tín hiệu này việc xác định các đỉnh gặp sai số dẫn đến không chẩn đoán được.

\section{Kết luận}

Bài báo trình bày một phương pháp hỗ trợ chẩn đoán hội chứng dày tâm thất và dày tâm nhĩ trên cơ sở xử lý tín hiệu điện tim ECG. Phương pháp được thực hiện dựa trên việc phát hiện các vị trí đỉnh cơ bản trong tín hiệu ECG, xác định các đặc trưng của sóng trên các chuyển đạo liên quan đến hội chứng dày tâm thất và dày tâm nhĩ. Một chương trình phần mềm chẩn đoán bệnh đã được xây dựng để thực thi phương pháp đề xuất. Kết quả thực nghiệm với các mẫu dữ liệu ECG đã khẳng định hiệu quả và tính khả thi khi ứng dụng trong thực tế.

\section{Tài liệu kham khảo}

[1] Malcolm S. Thaler, "The only EKG book", Lippincott Williams \& Wilinks, ISBN 978-45111905-3, 2012.

[2] Himanshu Gothwal1, Silky Kedawat1, Rajesh Kumar, "Cardiac arrhythmias detection in an ECG beat signal using fast fourier transform and artificial neural network", J. Biomedical Science and Engineering, 2011, 4, 289-296.

[3] El-Sayed A. El-Dahshan, "Genetic algorithm and wavelet hybrid scheme for ECG signal denoising", Journal of Telecommunications Systems, Volume 46 Issue 3, March 2011, pp 209-215.

[4] C. Li, C. Zheng, and C. Tai, "Detection of ECG characteristic points using wavelet transforms", IEEE Trans.Biomed. Eng, pp 21-28, 1995.

[5] A. K. M. Fazlul Haque1, Md. Hanif Ali1, M. Adnan Kiber2 and Md. Tanvir Hasan, "Detection of small variations of ECG features using Wavelet", ARPN Journal of Engineering and Applied Sciences, VoL. 4, No. 6, August 2009.

[6] Krimi Samar, Ouni Kas, Noureddine Ellouze, "Using Hidden Markov Models for ECG Characterisation", Hidden Markov Models, Theory and Applications, April 2011, pp 151-165.

[7] Trần Đỗ Trinh, Trần Văn Đồng, "Hướng dẫn đọc điện tim”, NXB Y học, Hà Nội, 2011. 


\title{
Coronary Artery Disease Diagnosis Based on Electrocardiogram Signal Analysis
}

\author{
Tran Nhu Chi ${ }^{1}$, Nguyen Thi Thanh Van ${ }^{1}$, Le Van Chieu ${ }^{2}$ \\ ${ }^{1}$ VNU University of Engineering and Technology, 144 Xuan Thuy, Hanoi, Vietnam \\ ${ }^{2}$ VNU Project Management Department, 144 Xuan Thuy, Hanoi, Vietnam
}

\begin{abstract}
An electrocardiogram (ECG) records and displays electrical impulses during cardiac activity. Studying the features of ECG signals to detect cardiac abnormalities is important in the medical field. This report presents a method for the detection of coronary artery diseases, i.e., Atrial Enlargement and Ventricular Enlargement, based on the analysis of ECG signals associated with standard indicators. A program performing ECG analysis for the detection of ventricular thickening and atrial thickening syndrome has been developed and verified with recorded ECG signal. The obtained results show a high accuracy diagnostic results, promising the ability to integrate the program into the ECG measuring equipment for screening and autonomus diagnosis.
\end{abstract}

Keywords: ECG, atrial enlargement and ventricular enlargement, signal processing. 